\title{
Pregnant people's perspectives on cannabis use during pregnancy: A systematic review and integrative mixed-methods research synthesis
}

\author{
Meredith Vanstone ${ }^{1}$, Janelle Panday ${ }^{1}$, Anuoluwa Popoola ${ }^{1}$, Shipra Taneja ${ }^{1}$, Devon \\ Greyson $^{2}$, Sarah McDonald ${ }^{1}$, Rachael Pack ${ }^{3}$, Morgan Black ${ }^{1}$, Beth Davis ${ }^{1}$, and Elizabeth \\ Darling ${ }^{1}$ \\ ${ }^{1}$ McMaster University \\ ${ }^{2}$ University of Massachusetts Amherst \\ ${ }^{3}$ Schulich School of Medicine and Dentistry
}

March 17, 2021

\begin{abstract}
Background: Cannabis use during the perinatal period is rising. Objectives: To synthesize existing knowledge on the perspectives of pregnant people and their partners about cannabis use in pregnancy and lactation. Search strategy: We searched MEDLINE, APA PsycINFO, Cumulative Index to Nursing and Allied Health Literature, Social Science Citation Index, Social Work Abstracts, ProQuest Sociology Collection up until April 1, 2020. Selection criteria: Eligible studies were those of any methodology which included the perspectives and experiences of pregnant or lactating people and their partners on cannabis use during pregnancy or lactation, with no time or geographical limit. Data collection and analysis: We employed a convergent integrative approach to the analysis of findings from all studies, using Sandelowski's technique of "qualitizing statements" to extract and summarize relevant findings from inductive analysis. Main results: We identified 23 studies of pregnant people's views about cannabis use in pregnancy. Comparative analysis revealed that whether cannabis was studied alone or grouped with other substances resulted in significant diversity in descriptions of participant decision-making priorities and perceptions of risks and benefits. Studies combining cannabis with other substance seldom addressed perceived benefits or reasons for using cannabis. Conclusions: The way cannabis is grouped with other substances influences the design and results of research. A comparative analysis emphasizes the importance of understanding why a pregnant person might choose to use cannabis in order to foster dialogue about perceptions of benefit and strategies for risk mitigation.
\end{abstract}

Pregnant people's perspectives on cannabis use during pregnancy: A systematic review and integrative mixed-methods research synthesis

Meredith Vanstone, ${ }^{\mathrm{a}}$ Janelle Panday, ${ }^{\mathrm{a} A n u o l u w a}$ Popoola, ${ }^{\mathrm{a}}$ Shipra Taneja, ${ }^{\mathrm{a} D e v o n}$ Greyson, ${ }^{\mathrm{b}}$ Sarah D. McDonald, ${ }^{\mathrm{c}, \mathrm{d}, \mathrm{e}}$ Rachael Pack, ${ }^{\mathrm{f}}$ Morgan Black, ${ }^{\mathrm{a}}$ Beth Murray-Davis,,${ }^{\mathrm{c}, \mathrm{g}}$ Elizabeth Darling ${ }^{\mathrm{c}, \mathrm{e}, \mathrm{g}}$

1. Department of Family Medicine, McMaster University, 100 Main St W, Hamilton, Ontario Canada L8P $1 \mathrm{H} 6$

2. Department of Communication, University of Massachusetts Amherst, 650 N. Pleasant St, Amherst, Massachusetts, United States of America

3. Department of Obstetrics and Gynecology, McMaster University, 1280 Main St W., Hamilton, Ontario, Canada L8S 4L8

4. Department of Radiology

5. Department of Health Research Methods, Evidence \& Impact 
6. Center for Education Research and Innovation, Schulich School of Medicine and Dentistry, Western University, 1151 Richmond St, London, Ontario, Canada, N6A 5C1

7. McMaster Midwifery Research Centre, McMaster University, 1280 Main St W., Hamilton, Ontario, Canada L8S 4L8

E-mail addresses for each author:

Meredith.vanstone@mcmaster.ca, pandayj@mcmaster.ca, popooa1@mcmaster.ca, tanejs1@mcmaster.ca, dgreyson@umass.edu, mcdonals@mcmaster.ca, rachael.pack@schulich.uwo.ca, morgan.black@medportal.ca, bmurray@mcmaster.ca, darlinek@mcmaster.ca

Corresponding author:

Meredith Vanstone, $\mathrm{PhD}$

Associate Professor

Department of Family Medicine

5001F, 100 Main St W

Hamilton, Ontario, Canada

L8S $1 \mathrm{H} 6$

Meredith.vanstone@mcmaster.ca

905-525-9140 x22113

3528 words (not including tables or references)

Running title: Perspectives of cannabis use in pregnancy

Abstract (242/250 words)

Background: Cannabis use during the perinatal period is rising.

Objectives: To synthesize existing knowledge on the perspectives of pregnant people and their partners about cannabis use in pregnancy and lactation.

Search strategy: We searched MEDLINE, APA PsycINFO, Cumulative Index to Nursing and Allied Health Literature, Social Science Citation Index, Social Work Abstracts, ProQuest Sociology Collection up until April 1, 2020.

Selection criteria: Eligible studies were those of any methodology which included the perspectives and experiences of pregnant or lactating people and their partners on cannabis use during pregnancy or lactation, with no time or geographical limit.

Data collection and analysis: We employed a convergent integrative approach to the analysis of findings from all studies, using Sandelowski's technique of "qualitizing statements" to extract and summarize relevant findings from inductive analysis.

Main results: We identified 23 studies describing the views of 9474 pregnant people and 613 postpartum about cannabis use in pregnancy. Comparative analysis revealed that whether cannabis was studied alone or grouped with other substances resulted in significant diversity in descriptions of participant decision-making priorities and perceptions of risks and benefits. Studies combining cannabis with other substance seldom addressed perceived benefits or reasons for using cannabis.

Conclusions: The way cannabis is grouped with other substances influences the design and results of research. A comparative analysis emphasizes the importance of understanding why a pregnant person might choose to use cannabis in order to foster dialogue about perceptions of benefit and strategies for risk mitigation. 
Funding: Canadian Institutes of Health Research

Key words: cannabis, pregnancy, lactation, systematic review, mixed-methods, integrative review

Prospero registration number: CRD42020180038

\section{Introduction:}

Cannabis use in pregnancy and during lactation has been increasing over time ${ }^{1-3}$, driven by increasing use in the general population ${ }^{4-6}$ and the likelihood of regular users to continue to use in pregnancy ${ }^{7,8}$. It is difficult to establish a precise rate of cannabis use during pregnancy, with existing studies suggesting that $2-36 \%$ of pregnant people use cannabis ${ }^{1-3,}, 7,9-12$ with variance related to the population studied, definition of use, and methodology. The prevalence of cannabis use during lactation is similarly unknown ${ }^{13,14}$.

Pregnant and lactating people use cannabis for a variety of reasons, including to treat conditions which both pre-exist and are related to the perinatal period ${ }^{7,8,11,15-19}$. Pregnant people report using cannabis to alleviate pregnancy-related conditions such as nausea, vomiting, pain and fatigue ${ }^{16,17,20}$. Others continue cannabis use for reasons which pre-existed pregnancy such as pain, anxiety, sleep, to control seizures, or for skin and hair treatment $7,8,11,15-18$. For some pregnant people cannabis use may be a method of harm reduction, to decrease the perceived negative impact of unmet physical or mental health needs, or as an aid to discontinue the use of other substances judged to be more harmful (e.g. opioids) ${ }^{21}$.

\section{Health Outcomes of Cannabis Use During Pregnancy}

For the pregnant or lactating person, negative health effects remain the same within and outside of pregnancy; harms include respiratory and cardiovascular disorders as well as mental health and addiction challenges ${ }^{22-27}$. There is evidence that pregnant cannabis users are at greater risk for anemia than non-pregnant users ${ }^{28}$.

Evidence about fetal harms of cannabis use during pregnancy is not yet clear. There have been contradictory findings on whether the use of cannabis during pregnancy has effects on birth weight, stillbirth or miscarriage, preterm birth and neonatal effects ${ }^{27-30}$. Meta-analyses have reported that some studies show a decrease in birth weight with cannabis use ${ }^{28,31,32}$, while others report no association ${ }^{27,29}$. There are also inconsistencies about whether cannabis use increases the risk for preterm delivery ${ }^{28,29}$, 32-34, or if it poses an increased risk for neonatal intensive care unit admission ${ }^{28,29,33}$. Prenatal exposure to cannabis may also affect longer term neurodevelopmental outcomes including attention, hyperactivity, impulsivity in early childhood ${ }^{34,35}$, emotional and behaviour problems ${ }^{35}$, and autism spectrum disorder ${ }^{36}$. Very few studies have analyzed the harms of cannabis exposure through lactation; there is conflicting evidence about the potential for delays in infant motor development ${ }^{27,37-39}$.

To help clinicians understand the decisional challenges about cannabis use faced by pregnant and lactating people, we conducted a systematic review to synthesize existing knowledge about how pregnant people's experiences, attitudes, and beliefs about cannabis use in pregnancy and during lactation.

\section{METHODS:}

We employed a convergent integrated approach to the synthesis of research using a variety of methods, following the Joanna Briggs Institute guidance. ${ }^{40,}{ }^{41}$ For this review, we sought primary, empirical studies to answer the following research question: What are the experiences, beliefs, and opinions of pregnant people and their partners about cannabis use during pregnancy and lactation? It is registered as PROSPERO review CRD42020180038.

\section{Search and Screening}

We sought English-language articles that used any method to gather and analyze primary, empirical data about the experiences, beliefs or opinions of pregnant people or their partners about cannabis use in pregnancy and lactation (Table 1). A search for published literature was performed by a medical librarian on April 01-02, 2020 using the following databases: MEDLINE, APA PsycINFO, Cumulative Index to Nursing and Allied Health Literature (CINAHL), Social Science Citation Index (SSCI), Social Work Abstracts, 
ProQuest Sociology Collection (including Sociological Abstracts). Grey literature searching was confined to theses, searched through the ProQuest Dissertation Abstracts database.

The search strategy (Appendix 1) comprised both controlled vocabulary and keywords and was peer-reviewed according to the PRESS checklist (Peer Review of Electronic Search Strategies). No limits to date or study design were applied. We also conducted a hand-search of eight relevant journals, described in Appendix 1.

Four reviewers (JP, AP, ST, MV) screened the titles and abstracts of all citations based on the eligibility criteria (Table 1). Full text articles were reviewed when more information was necessary to determine eligibility. Each article was screened independently by two reviewers and discrepancies were resolved through discussion with a third reviewer until consensus was reached. After identifying eligible articles, we traced citations forwards and backwards to identify additional eligible articles. PRISMA diagram depicting article selection process is in Figure 1.

\section{Critical Appraisal}

We conducted critical appraisal using the Mixed Methods Appraisal Tool (MMAT) ${ }^{42}$, selected as appropriate because it was designed to appraise studies with diverse designs and has been validated and reliability tested 43, 44. Each study was appraised independently by two reviewers (JP, MV, ED and a research assistant) who rated each aspect of the study as "yes", "no", or "can't tell" and conferred to reach consensus when they disagreed (Table 2). Consistent with this review methodology and with the MMAT tool, all eligible studies were included, as long as they presented data in evidence of their conclusions ${ }^{45-47}$.

\section{Data Extraction and Collation}

We extracted two types of data from each included study: 1) study characteristics and 2) study results relevant to the research question. Descriptive data about the study and participant characteristics was extracted into a standardized electronic form. This data was used for comparative and contextualization purposes during analysis.

Strategies for data analysis of studies in an integrative review are one of the least developed aspects of the process, because analysis is a highly interpretive process where analysts must be attuned to the particular range of data available in each individual study ${ }^{47,}{ }^{48}$. We used Sandelowski's method of "qualitizing" data by identifying and extracting findings and then transforming each finding into a portable declarative statement that is understandable on its own ${ }^{41,48}$. These declarative statements are constructed to integrate findings with information about the study deemed most relevant to characterizing those findings (e.g., population, jurisdiction). The declarative statements were composed by one reviewer and verified by another (JP, AP, $\mathrm{ST}, \mathrm{MV}$ ) and recorded on a data extraction sheet for the individual study.

\section{Data Analysis}

Results from all studies were analysed concurrently, following the convergent integrated approach in Hong's typology ${ }^{40}$. We treated the data in the "qualitized" declarative statements as qualitative data and used a staged constant comparative coding strategy adapted from Grounded Theory ${ }^{49}$, which we have previously used in integrative qualitative meta-synthesis ${ }^{45,50,51}$. This is an inductive approach to analysis which starts with initial rounds of coding to describe and condense the findings of individual studies. The analysts then proceed to generate categories from these descriptive codes and later move to a constant comparative analysis. During comparative analysis we paid attention to factors such as the legal status of cannabis, comparator substances, funding source, time of publication, sampling strategy, discipline of authors. Analysis was led by MV, JP, AP, ST. All analytic interpretations were negotiated during regular meetings with the whole research team.

\section{Results:}

We identified 23 eligible studies in this review, involving 9474 pregnant people and 613 postpartum or unspecified people. These studies were conducted in jurisdictions where cannabis was legal, decriminalized 
and illegal. Most studies were conducted in the United States of America, where states have varying cannabis laws, but cannabis remains federally illegal.

Concerning quality appraisal, the MMAT tool discourages the calculation of an overall score from the ratings of each category, but the quality of included papers was mostly acceptable ${ }^{42}$. As recommended, we present the rating for each criterion in Table 2 for the purposes of evaluating the strength of the conclusions of this synthesis. The included studies represent a variety of methodological approaches with roughly equal distribution of qualitative, quantitative, and mixed methods approaches (Table 4). The combined study populations of 10,087 were dominated by $\mathrm{Oh}$ et al $2017{ }^{52}$ which had 7627 participants. No partners were included in these studies and none of the postpartum participants were sampled for their experience or perspectives on using cannabis while breastfeeding (Table 4). Accordingly, our review of partner perspectives and the perspectives of lactating people is empty.

Our initial analysis of the entire dataset identified divergent findings across papers, and this divergence was not associated with critical appraisal results. As we engaged in comparative analysis, we identified that much of the divergence was accounted for by the other substances included in the study. When cannabis was studied alone, grouped with alcohol or tobacco, or grouped with other drugs, the focus and hence the findings of each study shifted. Accordingly, we present findings according to comparator groups (Table 5). We present a synthesis of evidence on three main themes that emerged through our inductive analysis: the main decisions faced by participants in these studies; descriptions of risk and benefit; descriptions of how information was sought and used (Table 6).

\section{Cannabis-only}

There were 12 studies that examined perspectives on cannabis use in pregnancy in isolation from any other substances ${ }^{8,20,52-61}$. These studies were conducted in the US, Canada, and Jamaica, in jurisdictions where recreational cannabis was legal or decriminalized $8,20,53,54,60$ as well as jurisdictions where it was illegal $55-59$.

Across these 12 papers, participants considered how to modulate their cannabis use to maximize benefit and minimize risk. Participants discussed changing the form of cannabis they used ${ }^{20,55,56}$, the amount ${ }^{20,54,56}$, or using cannabis at particular stages of pregnancy 8,60 to attain the perceived benefits while minimizing perceived risk.

Perceptions of the risks of cannabis were broad. Participants were consistently concerned about the risk of potential harms to their baby, both from the consumption of cannabis but also from the cessation or replacement of cannabis with a substance they deemed to be more harmful ${ }^{8,20,53,54,56,59,60}$. It is relevant here that many participants evaluated cannabis to carry less risk than over-the-counter or prescribed pharmaceuticals $20,54,55,59$. Participants also noted involvement with criminal justice or child welfare services as a risk of using cannabis $8,20,53-55,59-61$.

This group of studies was unique in its description of the perceived benefits of cannabis use in pregnancy. These benefits included managing conditions that pre-existed pregnancy including anxiety, depression, bipolar disorder, substance use disorders, PTSD, insomnia, anemia, chronic pain, Helicobacter pylori, osteoarthritis, fibromyalgia ${ }^{20,54,61}$, or improving general health and mental, physical, and spiritual well-being 56,61 . Benefits also included managing conditions related to pregnancy, including nausea and vomiting, weight gain, sleep, pain related to the physical toll of pregnancy or labour, stress related to pregnancy and parenting $8,20,54-56,60,61$.

Participant decisions about whether, when, and how to consume cannabis were also influenced by their pre-pregnancy habits or reasons for use including improving mood, providing pleasure, managing stress, and making difficult circumstances more tolerable ${ }^{20,54-56}$. The financial implications of cannabis use were mentioned as influencing both decisions to use and cease using ${ }^{8,57}$. Support or disapproval from friends, family, and healthcare professionals could also be influential ${ }^{8,57}$.

The sources, types, and evaluation of information was a common topic in this group of papers. Pregnant 
people sought information from healthcare providers ${ }^{53,55}$, the internet $20,55,59,61$, and friends and family 55,59 , as well as cannabis retailers ${ }^{20,53}$. Reconciling diverse and conflicting information was necessary, and participants described contradictions between what they heard from healthcare providers, read about online, and experienced personally or heard anecdotally from others ${ }^{20,59}$. Participants in several studies expressed disappointment at the lack of clarity regarding the safety of using cannabis in pregnancy, describing the available information as confusing, inconsistent, and incomplete $20,54,55,57,59$.

\section{Cannabis, alcohol and tobacco}

Three studies examined cannabis use in pregnancy alongside alcohol and tobacco in the US and Australia, where non-medical cannabis was illegal ${ }^{62-64}$. In these papers, the main decision participants considered was whether or not to cease or decrease their pre-pregnancy cannabis consumption rate during pregnancy ${ }^{62-64}$. One paper also addressed resuming or changing patterns of use postpartum ${ }^{64}$.

The harms of cannabis use during pregnancy are a main focus of this research. Participants considered harm to the fetus as a primary concern, with harm to own health, addiction, stress and withdrawal symptoms from quitting also addressed ${ }^{62-64}$. Few benefits of cannabis use were discussed, but individual participants in the studies mentioned using cannabis to treat depression and other medical problems ${ }^{63}$ or to manage stress and forget problems ${ }^{63,64}$.

When considering whether to stop or reduce use, social factors were important with the level of concern from family and friends mentioned as influential in all papers ${ }^{62-64}$. Intervention or counselling from healthcare providers was motivating for some participants ${ }^{64}$. Information-seeking was not mentioned in any article. Despite the fact that recreational cannabis was illegal in all jurisdictions where these studies were conducted, legal implications are not mentioned in these studies.

\section{Cannabis and other illicit substances}

Six studies discussed cannabis alongside other illicit substances ${ }^{65-70}$. These papers did not have defined groups of substances, but rather studied perspectives or experiences with substance use in pregnancy more generally, offering long lists of the substances that participants discussed. Five of these studies were conducted in the United States ${ }^{65,66,68-70}$, and one in Canada ${ }^{67}$. In this collection of studies, medical cannabis use was legal in all but one jurisdiction ${ }^{65}$ and recreational use was illegal in all but one jurisdiction. ${ }^{70}$ Of these six articles, five sampled participants from perinatal substance abuse treatment programs ${ }^{65,67-70}$. One recruited from public agencies and community organizations ${ }^{66}$. This collection of studies started from the assumption that abstaining from substance use was necessary and desirable, and examined the barriers and facilitators of quitting. Accordingly, the main decision posed to participants in these studies was not whether to quit but how .

Perceptions of the risks of substance use in pregnancy were frequently discussed. Participants discussed drugrelated arrests and criminal involvement, including fear that child protective services would take away their child ${ }^{66-70}$. Participants also discussed perceptions of the harm to the fetus, and to their ability to parent other children, and their feelings of worry or guilt about this ${ }^{66-70}$. Some participants denied feeling worried about harming their baby, citing other children they knew to be prenatally exposed to similar substances without notable harm ${ }^{70}$. Healthcare providers were often viewed as a source of punishment, rather than protection or resources ${ }^{68,69}$.

There was very little discussion of why participants chose to use substances, or what benefits they may have experienced. This topic is only present in the quotes from individual participants and not addressed by the authors. Relationships with other people who use substances was cited as a factor which normalized and made substances difficult to quit, although this was framed as a barrier to quitting rather than a benefit of use $67,69,70$.

Because the main decision considered was how to quit, notwhether to quit, the influential factors in this decision focused on available support and resources to quit, and perceptions of self-efficacy about quitting ${ }^{65-70}$. Similarly, content about information use focused on the identification of resources to support cessation 
and parenting $67,69,70$. Typically, these sources were related to the substance-abuse program the participants were enrolled in at the time of recruitment.

\section{Cannabis and herbal medicines}

We identified two Canadian manuscripts describing a single group of participants who used herbal medicines in pregnancy 71,72 . The main decision faced by participants in these studies was what to use to control pregnancy-related symptoms including nausea and vomiting. Cannabis was one herbal remedy considered and used by participants and was discussed alongside ginger, peppermint, and other herbal medicines. When making the decision about what to use to control nausea and vomiting, participants discussed risks to the fetus as a primary concern and efficacy of the herbal medicine as a secondary concern ${ }^{71,72}$.

Information used to make the decision included prior knowledge, trusted sources of advice (friends, family, healthcare providers, herbalists, the internet) and intuition/instinct ${ }^{71}$. Participants were more comfortable using herbs than pharmaceutical drugs and would only turn to pharmaceutical products after herbal medicines had failed ${ }^{71}$. Medical cannabis was legal but recreational cannabis was illegal in this jurisdiction at the time of the research; legal implications are not discussed in these papers ${ }^{71,} 72$.

\section{Discussion}

We identified 23 studies that describe the perspectives of just over 10,000 pregnant people about the reasons for, risks and benefits of, and available information about cannabis use during pregnancy. We did not identify any studies about the perspectives of lactating people about using cannabis during lactation, nor did we identify any studies about the perspectives of partners on the use of cannabis during pregnancy or lactation.

This review demonstrates the powerful nature of the study design on research findings. When cannabis is included as one illicit drug used by someone enrolled in a substance abuse treatment program, the considerations and priorities are very different than when it is included as an herbal medicine used by someone seeking a non-pharmaceutical remedy for nausea and vomiting in pregnancy. Many studies did not describe the reasons why a person may seek to use cannabis during pregnancy, or the benefits that users experience from this substance. Most studies focused on smoked cannabis, and do not investigate perceptions of risks other forms of cannabis products (e.g. oils, topical applications, low-THC products).

Concern with fetal harm from prenatal cannabis exposure is a common theme in this literature. Strikingly, cannabis is almost always compared by study authors to substances where strong evidence of fetal harm exists (e.g., alcohol, tobacco, methamphetamines, opioids). This comparison is carried through to public health and clinical materials which also commonly group cannabis with these substances, belying the emergent and equivocal nature of evidence of fetal harm. These common groupings illuminate the assumptions of researchers but make it difficult to see that pregnant people may not understand cannabis the same way. For example, in one included study, participants compared cannabis to caffeine and fast food, two substances which are sub-optimal, but fulfill important social and emotional functions for pregnant people ${ }^{20}$.

The precautionary principle holds that when evidence is uncertain, the appropriate course of action is to err on the side of caution ${ }^{73}$. Given the evidence showing the potential for deleterious effects of cannabis use during pregnancy and lactation, the ideal outcome would be to reduce or eliminate cannabis consumption during these periods. However, as participants in many of the included papers described, many receive benefits from using cannabis and fear that ceasing use may result in greater harm.

Clinicians working with pregnant people who are considering cannabis use may wish to adopt a harm reduction approach. Harm reduction is particularly relevant in obstetrical settings where the decision-maker is not the only person affected by choices about substance use. A harm reduction approach accepts the inevitability of drug use and works with users to minimize the associated harms ${ }^{74}$. Given the documented perceptions of benefit and the lack of certainty about harm of cannabis use in pregnancy, we encourage clinicians and researchers to inquire about why a person wishes to use cannabis, what benefits they receive from use. Discussions of risk and benefit should go beyond physiological impact and include the availability of support, personal care, agency, and emotional health ${ }^{75}$. A strong relationship between clinicians and 
their pregnant clients will be beneficial in order to identify appropriate strategies for harm reduction, which may include reducing or quitting use, substituting other drugs or treatments, making a lifestyle change and seeking consistent prenatal care ${ }^{74,76}$.

Areas for future research

Our review identified no studies on the perspectives of the partners of pregnant people about cannabis use in pregnancy, although the influence of friends and family was noted as important by several studies. We also identified no research on opinions, beliefs, or experiences of lactating people, or their partners about cannabis consumption.

\section{Strengths and Limitations}

There are two existing systematic reviews on similar topics ${ }^{15,19}$, each with fewer than 6 included studies. Our search strategy, including extensive hand-searching and citation list searching is a strength, yielding 23 included studies, only 4 of which overlap with studies included in these previous reviews. This study has a few limitations. We searched only for articles published in English. We only included studies with participants who had personal experience of pregnancy or breastfeeding, potentially excluding the important perspectives of cannabis users who have yet to become pregnant.

\section{Conclusion}

There is a growing body of evidence about the perspectives of pregnant people on cannabis use in pregnancy, but this literature does not yet include the perspectives of their partners, or perspectives about the use of cannabis during lactation. Many studies do not acknowledge that there are specific reasons that people choose to use cannabis during pregnancy, and a host of perceived benefits to this use. This gap may reflect the influence of the researcher's assumptions about cannabis use on the study design of existing evidence. As cannabis use rates rise in many jurisdictions following legalization, additional research on the ways and reasons that people use cannabis during the perinatal period is necessary to encourage informed decisions that reduce risk to pregnant people and their future children.

Acknowledgments: Caroline Higgins designed and conducted the literature search. Meera Mahmud assisted with critical appraisal.

Disclosure of Interests : There are no conflicts to declare.

Contribution to Authorship: MV, SM, MB, BMD, ED secured funding. MV, SM, DG, SM, RP, MB, BMD, ED designed the study. MV, JP, AP, ST collected data. MV, JP, AP, ST led analysis, with contributions from SM, DG, SM, RP, MB, BMD, ED. MV drafted the manuscript, which was critically revised by JP, AP, ST, DG, SM, RP, MB, BMD, ED. All authors approved the final version to be submitted and agree to be accountable for the content.

Ethical Approval: All data were in the public domain so ethical approval was not required.

Funding: This study was funded by the Canadian Institutes of Health Research, who had no role in the design, conduct, or reporting of the research.

\section{REFERENCES}

1. Brown QL, Sarvet AL, Shmulewitz D, Martins SS, Wall MM, Hasin DS. Trends in marijuana use among pregnant and nonpregnant reproductive-aged women, 2002-2014. Jama. 2017;317(2):207-9.

2. Petrangelo A, Czuzoj-Shulman N, Balayla J, Abenhaim HA. Cannabis Abuse or Dependence During Pregnancy: A Population-Based Cohort Study on 12 Million Births. Journal of Obstetrics and Gynaecology Canada. 2019;41(5):623-30.

3. Young-Wolff KC, Tucker L-Y, Alexeeff S, Armstrong MA, Conway A, Weisner C, et al. Trends in selfreported and biochemically tested marijuana use among pregnant females in California from 2009-2016. Jama. 2017;318(24):2490-1. 
4. Cerdá M, Wall M, Keyes KM, Galea S, Hasin D. Medical marijuana laws in 50 states: investigating the relationship between state legalization of medical marijuana and marijuana use, abuse and dependence. Drug and alcohol dependence. 2012;120(1-3):22-7.

5. Statistics Canada. National Cannabis Survey. Ottawa, ON: Statistics Canada; 2019.

6. Statistics Canada. Canadian Tobacco, Alcohol and Drugs Survey: Summary of results for 2017. Ottawa, ON: Government of Canada; 2017.

7. Beatty JR, Svikis DS, Ondersma SJ. Prevalence and perceived financial costs of marijuana versus tobacco use among urban low-income pregnant women. Journal of addiction research \& therapy. 2012;3(4).

8. Mark K, Gryczynski J, Axenfeld E, Schwartz RP, Terplan M. Pregnant women's current and intended cannabis use in relation to their views toward legalization and knowledge of potential harm. Journal of addiction medicine. 2017;11(3):211-6.

9. Corsi DJ, Hsu H, Weiss D, Fell DB, Walker M. Trends and correlates of cannabis use in pregnancy: a population-based study in Ontario, Canada from 2012 to 2017. Canadian Journal of Public Health. 2019;110(1):76-84.

10. McLaughlin J, Castrodale L. Marijuana Use among Women Delivering Live Births in Alaska, 2002-2011.

11. Ko JY, Farr SL, Tong VT, Creanga AA, Callaghan WM. Prevalence and patterns of marijuana use among pregnant and nonpregnant women of reproductive age. American journal of obstetrics and gynecology. 2015;213(2):201. e1-. e10.

12. Muckle G, Laflamme D, Gagnon J, Boucher O, Jacobson JL, Jacobson SW. Alcohol, smoking, and drug use among Inuit women of childbearing age during pregnancy and the risk to children. Alcoholism: Clinical and Experimental Research. 2011;35(6):1081-91.

13. Astley SJ, Little RE. Maternal marijuana use during lactation and infant development at one year. Neurotoxicology and teratology. 1990;12(2):161-8.

14. Crume TL, Juhl AL, Brooks-Russell A, Hall KE, Wymore E, Borgelt LM. Cannabis use during the perinatal period in a state with legalized recreational and medical marijuana: The association between maternal characteristics, breastfeeding patterns, and neonatal outcomes. The Journal of pediatrics. 2018;197:90-6.

15. Bayrampour H, Zahradnik M, Lisonkova S, Janssen P. Women's perspectives about cannabis use during pregnancy and the postpartum period: An integrative review. Preventive medicine. 2018.

16. Young-Wolff KC, Sarovar V, Tucker L-Y, Avalos LA, Conway A, Armstrong MA, et al. Association of nausea and vomiting in pregnancy with prenatal marijuana use. JAMA internal medicine. 2018;178(10):14234 .

17. Roberson EK, Patrick WK, Hurwitz EL. Marijuana Use and Maternal Experiences of Severe Nausea During Pregnancy in Hawai 'i. Hawai'i Journal of Medicine \& Public Health. 2014;73(9):283.

18. Greyson D, Roosevelt L, C B. Desistance, self-treatment, or substitution: Decisions about cannabis use during pregnancy. Journal of Midwifery \& Women's Health. 2021(DOI: 10.1111/jmwh.13205).

19. Weisbeck SJ, Bright KS, Ginn CS, Smith JM, Hayden KA, Ringham C. Perceptions about cannabis use during pregnancy: a rapid best-framework qualitative synthesis. Canadian Journal of Public Health. 2020:1-11.

20. Barbosa-Leiker C, Burduli E, Smith CL, Brooks O, Orr M, Gartstein M. Daily Cannabis Use During Pregnancy and Postpartum in a State With Legalized Recreational Cannabis. Journal of Addiction Medicine. 2020 Jan 31;31:31. 
21. Benoit C, Magnus S, Phillips R, Marcellus L, Charbonneau S. Complicating the dominant morality discourse: mothers and fathers' constructions of substance use during pregnancy and early parenthood. International journal for equity in health. 2015;14(1):72.

22. Karila L, Roux P, Rolland B, Benyamina A, Reynaud M, Aubin HJ, et al. Acute and long-term effects of cannabis use: a review. Curr Pharm Des. 2014;20(25):4112-8.

23. Volkow ND, Baler RD, Compton WM, Weiss SRB. Adverse health effects of marijuana use. N Engl J Med. 2014;370(23):2219-27.

24. Cohen K, Weizman A, Weinstein A. Positive and Negative Effects of Cannabis and Cannabinoids on Health. Clinical Pharmacology \& Therapeutics. 2019;105(5):1139-47.

25. Hall W. What has research over the past two decades revealed about the adverse health effects of recreational cannabis use? Addiction. 2015 Jan;110(1):19-35.

26. Memedovich KA, Dowsett LE, Spackman E, Noseworthy T, Clement F. The adverse health effects and harms related to marijuana use: an overview review. CMAJ open. 2018 Jul-Sep;6(3):E339-E46.

27. Badowski S, Smith G. Cannabis use during pregnancy and postpartum. Canadian Family Physician. 2020 Feb;66(2):98-103.

28. Gunn JK, Rosales CB, Center KE, Nunez A, Gibson SJ, Christ C, et al. Prenatal exposure to cannabis and maternal and child health outcomes: a systematic review and meta-analysis. BMJ Open. 2016 Apr 05;6(4):e009986.

29. Thompson R, DeJong K, Lo J. Marijuana Use in Pregnancy: A Review. Obstetrical \& Gynecological Survey. 2019 Jul;74(7):415-28.

30. Stickrath E. Marijuana Use in Pregnancy: An Updated Look at Marijuana Use and Its Impact on Pregnancy. Clinical Obstetrics \& Gynecology. 2019 03;62(1):185-90.

31. Bailey BA, Wood DL, Shah D. Impact of pregnancy marijuana use on birth outcomes: results from two matched population-based cohorts. Journal of Perinatology. 2020 Mar 05;05:05.

32. Alharbi FF, el-Guebaly N. Exploring the management of cannabis use among women and during pregnancy. Addictive Disorders \& Their Treatment. 2014 2014;13(2):93-100.

33. Metz TD, Borgelt LM. Marijuana Use in Pregnancy and While Breastfeeding. Obstetrics \& Gynecology. 2018 11;132(5):1198-210.

34. Committee Opinion No. 722: Marijuana Use During Pregnancy and Lactation. Obstetrics \& Gynecology. 2017;130(4):e205-e9.

35. Marroun HE, Bolhuis K, Franken IHA, Jaddoe VWV, Hillegers MH, Lahey BB, et al. Preconception and prenatal cannabis use and the risk of behavioural and emotional problems in the offspring; a multi-informant prospective longitudinal study. International Journal of Epidemiology. 2019;48(1):287-96.

36. Corsi DJ, Donelle J, Sucha E, Hawken S, Hsu H, El-Chaâr D, et al. Maternal cannabis use in pregnancy and child neurodevelopmental outcomes. Nature Medicine. 2020 2020/08/10.

37. Astley SJ, Little RE. Maternal marijuana use during lactation and infant development at one year. Neurotoxicol Teratol. 1990 Mar-Apr;12(2):161-8.

38. Ordean A, Kim G. Cannabis Use During Lactation: Literature Review and Clinical Recommendations. J Obstet Gynaecol Can. 2020 Jan 25;25:25.

39. Tennes K, Avitable N, Blackard C, Boyles C, Hassoun B, Holmes L, et al. Marijuana: prenatal and postnatal exposure in the human. NIDA Res Monogr. 1985;59:48-60. 
40. Hong QN, Pluye P, Bujold M, Wassef M. Convergent and sequential synthesis designs: implications for conducting and reporting systematic reviews of qualitative and quantitative evidence. Systematic reviews. $2017 ; 6(1): 61$.

41. Lizarondo L, Stern C, Carrier J, Godfrey C, Rieger K, Salmond S, et al. Mixed methods systematic reviews. . In: Aromataris E, Munn Z, editors. Joanna Briggs Institute Reviewer's Manual: The Joanna Briggs Institute; 2019.

42. Hong QN, Fàbregues S, Bartlett G, Boardman F, Cargo M, Dagenais P, et al. The Mixed Methods Appraisal Tool (MMAT) version 2018 for information professionals and researchers. Education for Information. 2018;34(4):285-91.

43. Pace R, Pluye P, Bartlett G, Macaulay AC, Salsberg J, Jagosh J, et al. Testing the reliability and efficiency of the pilot Mixed Methods Appraisal Tool (MMAT) for systematic mixed studies review. International journal of nursing studies. 2012;49(1):47-53.

44. Souto RQ, Khanassov V, Hong QN, Bush PL, Vedel I, Pluye P. Systematic mixed studies reviews: updating results on the reliability and efficiency of the mixed methods appraisal tool. Int J Nurs Stud. 2015;52(1):500-1.

45. Sandelowski M BJ. Handbook for synthesizing qualitative research.: New York: Springer Publishing; 2006 .

46. Majid U, Vanstone M. Appraising qualitative research for evidence syntheses: a compendium of quality appraisal tools. Qualitative health research. 2018;28(13):2115-31.

47. Whittemore R, Knafl K. The integrative review: updated methodology. Journal of advanced nursing. 2005;52(5):546-53.

48. Sandelowski M, Leeman J, Knafl K, Crandell JL. Text-in-context: a method for extracting findings in mixed-methods mixed research synthesis studies. Journal of Advanced Nursing. 2013;69(6):1428-37.

49. Charmaz K. Constructing grounded theory: a practical guide through qualitative analysis. London: Sage Publications; 2006.

50. Sandelowski M BJ. Creating metasummaries of qualitative findings. Nursing Research. 2003;52(4):22633.

51. Sandelowski M BJ. Toward a metasynthesis of qualitative findings on motherhood in HIV-positive women. Research in Nursing and Health. 2003;26(2):153-70.

52. Oh S, Salas-Wright CP, Vaughn MG, DiNitto DM. Marijuana use during pregnancy: A comparison of trends and correlates among married and unmarried pregnant women. Drug Alcohol Depend. 201712 01;181:229-33.

53. Bartlett K, Kaarid K, Gervais N, Vu N, Sharma S, Patel T, et al. Pregnant Canadians' perceptions about the transmission of cannabis in pregnancy and while breastfeeding and the impact of information from healthcare providers on discontinuation of use. Journal of Obstetrics and Gynaecology Canada. 2020 $2020 / 05 / 15 /$.

54. Chang JC, Tarr JA, Holland CL, De Genna NM, Richardson GA, Rodriguez KL, et al. Beliefs and attitudes regarding prenatal marijuana use: Perspectives of pregnant women who report use. Drug Alcohol Depend. 201903 01;196:14-20.

55. Curry WL. Hyperemesis gravidarum and clinical cannabis: to eat or not to eat? Journal of Cannabis Therapeutics. 2002;2(3/4):63-83.

56. Dreher MC. Poor and pregnant: perinatal ganja use in rural Jamaica. Adv Alcohol Subst Abuse. $1989 ; 8(1): 45-54$. 
57. Gray J, Beatty JR, Svikis DS, Puder KS, Resnicow K, Konkel J, et al. Electronic Brief Intervention and Text Messaging for Marijuana Use During Pregnancy: Initial Acceptability of Patients and Providers. JMIR Mhealth Uhealth. 2017 Nov 08;5(11):e172.

58. Holland CL, Nkumsah MA, Morrison P, Tarr JA, Rubio D, Rodriguez KL, et al. "Anything above marijuana takes priority": Obstetric providers' attitudes and counseling strategies regarding perinatal marijuana use. Patient Educ Couns. 2016 09;99(9):1446-51.

59. Jarlenski M, Tarr JA, Holland CL, Farrell D, Chang JC. Pregnant Women's Access to Information About Perinatal Marijuana Use: A Qualitative Study. Womens Health Issues. 2016 Jul-Aug;26(4):452-9.

60. Postonogova T, Xu C, Moore A. Marijuana During Labour: A Survey of Maternal Opinions. J Obstet Gynaecol Can. 2020 Jan 27;27:27.

61. Young-Wolff KC, Gali K, Sarovar V, Rutledge GW, Prochaska JJ. Women's Questions About Perinatal Cannabis Use and Health Care Providers' Responses. J Womens Health (Larchmt). 2020 Jan 30;30:30.

62. Beatty JR, Svikis DS, Ondersma SJ. Prevalence and Perceived Financial Costs of Marijuana versus Tobacco use among Urban Low-Income Pregnant Women. Journal of Addiction Research \& Therapy. 2012 Sep 30;3(4):30.

63. Hotham ED, Ali RL, White JM. Analysis of qualitative data from the investigation study in pregnancy of the ASSIST Version 3.0 (the Alcohol, Smoking and Substance Involvement Screening Test). Midwifery. 2016 Mar;34:183-97.

64. Morrison DM, Spencer MS, Gillmore MR. Beliefs about substance use among pregnant and parenting adolescents. Journal of Research on Adolescence. 1998;8(1):69-95.

65. Higgins PG, Clough DH, Wallerstedt C. DRUG-TAKING BEHAVIORS OF PREGNANT SUBSTANCEABUSERS IN TREATMENT. Journal of Advanced Nursing. 1995 Sep;22(3):425-32.

66. Klein D, Crim D, Zahnd E. Perspectives of pregnant substance-using women: Findings from the California perinatal needs assessment. Journal of Psychoactive Drugs. 1997 Jan-Mar;29(1):55-66.

67. Latuskie KA, Andrews NCZ, Motz M, Leibson T, Austin Z, Ito S, et al. Reasons for substance use continuation and discontinuation during pregnancy: A qualitative study. Women and Birth. 2019 2019/02/01/;32(1):e57-e64.

68. Roberts SC, Nuru-Jeter A. Women's perspectives on screening for alcohol and drug use in prenatal care. Womens Health Issues. 2010 May-Jun;20(3):193-200.

69. Roberts SCM, Pies C. Complex calculations: how drug use during pregnancy becomes a barrier to prenatal care. Matern Child Health J. 2011;15(3):333-41.

70. Van Scoyoc A, Harrison J, Fisher P. Beliefs and Behaviors of Pregnant Women with Addictions Awaiting Treatment Initiation. Child and Adolescent Social Work Journal. 2016 11/17;34.

71. Westfall RE. Herbal healing in pregnancy: women's experiences. Journal of herbal pharmacotherapy. 2003;3(4):17-39.

72. Westfall RE. Use of anti-emetic herbs in pregnancy: women's choices, and the question of safety and efficacy. Complementary therapies in nursing and midwifery. 2004;10(1):30-6.

73. Chaudry RV. The precautionary principle, public health, and public health nursing. Public Health Nursing. 2008;25(3):261-8.

74. Rosenbaum M, Irwin K. Pregnancy, drugs, and harm reduction. Drug addiction research and the health of women Rockville, MD: National Institute on Drug Abuse. 1998:309-18. 
75. Pauly B. Harm reduction through a social justice lens. International Journal of Drug Policy. 2008;19(1):410.

76. Wright TE, Schuetter R, Fombonne E, Stephenson J, Haning WF. Implementation and evaluation of a harm-reduction model for clinical care of substance using pregnant women. Harm reduction journal. 2012;9(1):5.

Table 1: Eligibility Criteria (suggest print \#1)

\begin{tabular}{lll}
\hline & Inclusion & Exclus \\
\hline Population & Pregnant or lactating people and/or their partners & Partici] \\
Topic & Participant attitudes, perceptions, or beliefs about cannabis use during pregnancy and/or lactation & Genera \\
Methods & Any methods for gathering and analyzing primary, empirical data & Non-en \\
Language & English & Any ot \\
Date Range & Any & N/A \\
\hline
\end{tabular}

Table 2: Critical Appraisal Results - Quality evaluation of included studies using the Mixed Methods Appraisal Tool (2018 Version) (suggest print \#2)

\begin{tabular}{|c|c|c|c|c|c|c|}
\hline & $\begin{array}{l}\text { Qualitative } \\
1.1\end{array}$ & $\begin{array}{l}\text { Qualitative } \\
1.2\end{array}$ & $\begin{array}{l}\text { Qualitative } \\
1.3\end{array}$ & $\begin{array}{l}\text { Qualitative } \\
1.4\end{array}$ & $\begin{array}{l}\text { Qualitative } \\
1.5\end{array}$ & $\begin{array}{l}\text { Quantitative Descriptive } \\
2.1\end{array}$ \\
\hline Barbosa-Leiker $^{20}(2020)$ & $\mathrm{Y}$ & $\mathrm{Y}$ & $\mathrm{Y}$ & $\mathrm{Y}$ & $\mathrm{Y}$ & \\
\hline Bartlett $^{53}(2020)$ & & & & & & $\mathrm{Y}$ \\
\hline Beatty $^{62}(2012)$ & & & & & & $\mathrm{Y}$ \\
\hline Chang $^{54}(2019)$ & $\mathrm{Y}$ & $\mathrm{Y}$ & $\mathrm{Y}$ & Y & $\mathrm{Y}$ & \\
\hline Curry $^{55}(2002)$ & $\mathrm{Y}$ & $\mathrm{C}$ & $\mathrm{N}$ & $\mathrm{N}$ & $\mathrm{C}$ & \\
\hline Dreher $^{56}(1988)$ & $\mathrm{Y}$ & $\mathrm{C}$ & $\mathrm{Y}$ & $\mathrm{Y}$ & $\mathrm{C}$ & \\
\hline Gray $^{57}(2017)$ & $\mathrm{Y}$ & $\mathrm{Y}$ & $\mathrm{Y}$ & $\mathrm{Y}$ & $\mathrm{Y}$ & $\mathrm{C}$ \\
\hline Higgins $^{65}(1995)$ & $\mathrm{Y}$ & $\mathrm{Y}$ & $\mathrm{Y}$ & $\mathrm{Y}$ & $\mathrm{C}$ & $\mathrm{Y}$ \\
\hline Holland $^{58}(2016)$ & & & & & & $\mathrm{C}$ \\
\hline Hotham $^{63}(2016)$ & $\mathrm{N}$ & $\mathrm{N}$ & $\mathrm{Y}$ & $\mathrm{Y}$ & $\mathrm{Y}$ & \\
\hline Jarlenski $^{59}$ (2016) & $\mathrm{Y}$ & $\mathrm{Y}$ & $\mathrm{Y}$ & $\mathrm{Y}$ & $\mathrm{Y}$ & \\
\hline Klein 66 (1997) & & & & & & $\mathrm{Y}$ \\
\hline Latuskie $^{67}$ (2018) & $\mathrm{N}$ & $\mathrm{N}$ & $\mathrm{Y}$ & $\mathrm{Y}$ & $\mathrm{Y}$ & \\
\hline $\operatorname{Mark}^{8}(2017)$ & & & & & & $\mathrm{Y}$ \\
\hline Morrison $^{64}$ (1998) & & & & & & $\mathrm{Y}$ \\
\hline $\mathrm{Oh}^{52}(2017)$ & & & & & & $\mathrm{Y}$ \\
\hline Postonogova $^{60}(2020)$ & & & & & & $\mathrm{Y}$ \\
\hline Roberts $^{68}(2010)$ & $\mathrm{Y}$ & $\mathrm{C}$ & $\mathrm{Y}$ & Y & $\mathrm{Y}$ & \\
\hline Roberts $^{69}(2011)$ & $\mathrm{Y}$ & $\mathrm{C}$ & $\mathrm{Y}$ & $\mathrm{Y}$ & $\mathrm{Y}$ & \\
\hline Van Scoyoc ${ }^{70}(2017)$ & $\mathrm{Y}$ & $\mathrm{Y}$ & $\mathrm{Y}$ & $\mathrm{Y}$ & $\mathrm{Y}$ & \\
\hline Westfall $^{72}(2004)$ & $\mathrm{Y}$ & $\mathrm{Y}$ & $\mathrm{Y}$ & $\mathrm{N}$ & $\mathrm{N}$ & \\
\hline Westfall $^{71}(2003)$ & $\mathrm{Y}$ & $\mathrm{Y}$ & $\mathrm{Y}$ & $\mathrm{Y}$ & $\mathrm{Y}$ & \\
\hline Young-Wolff $^{61}(2020)$ & $\mathrm{Y}$ & $\mathrm{Y}$ & $\mathrm{Y}$ & $\mathrm{Y}$ & $\mathrm{Y}$ & $\mathrm{Y}$ \\
\hline
\end{tabular}

$\mathrm{Y}=$ Yes; $\mathrm{N}=\mathrm{No} ; \mathrm{C}=$ Can't Tell. Detailed descriptions of each criterion are published elsewhere. (42)

Table 3: Description of each included study (organized by Comparator Group) (suggest online only b/c longer than 1 page) 


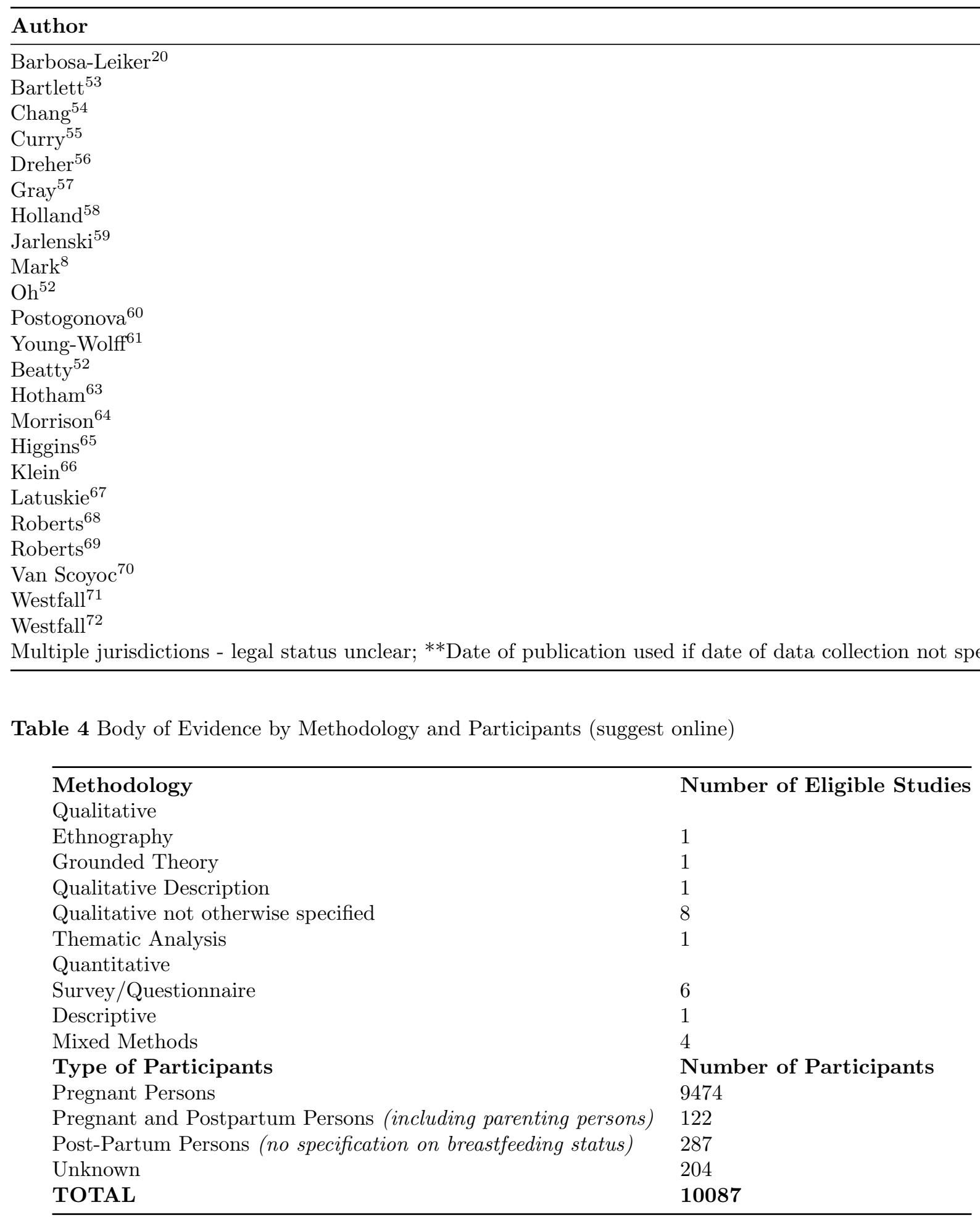

Table 5: Comparator Group (suggest print \#3)

Group 1 - Cannabis only Group 2 - Cannabis, Alcohol, Tobacco Group 3 - Cannabis and other illicit sul 


\begin{tabular}{|c|c|c|}
\hline Barbosa-Leiker ${ }^{20}$ & Beatty $^{62}$ & Higgins $^{65}$ \\
\hline Bartlett $^{53}$ & Hotham $^{63}$ & Klein 66 \\
\hline Chang $^{54}$ & Morrison $^{64}$ & Latuskie $^{67}$ \\
\hline Curry 55 & & Roberts $(2010)^{68}$ \\
\hline Dreher $^{56}$ & & Roberts $(2011)^{69}$ \\
\hline Gray $^{57}$ & & Van Scoyoc ${ }^{70}$ \\
\hline Holland 58 & & \\
\hline Jarlenski $^{59}$ & & \\
\hline $\operatorname{Mark}^{8}$ & & \\
\hline $\mathrm{Oh}^{52}$ & & \\
\hline Postogonova $^{60}$ & & \\
\hline Young-Wolff 61 & & \\
\hline
\end{tabular}

Table 6: Main themes organized by comparator group (suggest print \#4)

\begin{tabular}{|c|c|c|c|c|}
\hline Main Themes & $\begin{array}{l}\text { Group } 1 \text { - } \\
\text { Cannabis only }\end{array}$ & $\begin{array}{l}\text { Group } 2 \text { - } \\
\text { Cannabis, } \\
\text { Alcohol, } \\
\text { Tobacco }\end{array}$ & $\begin{array}{l}\text { Group } 3 \text { - } \\
\text { Cannabis and } \\
\text { other illicit } \\
\text { substances }\end{array}$ & $\begin{array}{l}\text { Group } 4 \text { - } \\
\text { Cannabis and } \\
\text { herbal } \\
\text { medicines }\end{array}$ \\
\hline $\begin{array}{l}\text { Main decision } \\
\text { considered by } \\
\text { participants }\end{array}$ & $\begin{array}{l}\text { How to modulate } \\
\text { cannabis use to } \\
\text { maximize benefits } \\
\text { and minimize } \\
\text { risks. }\end{array}$ & $\begin{array}{l}\text { Whether or not to } \\
\text { cease or decrease } \\
\text { cannabis use in } \\
\text { pregnancy. }\end{array}$ & $\begin{array}{l}\text { How to quit } \\
\text { substance use and } \\
\text { the barriers and } \\
\text { facilitators to } \\
\text { quitting. }\end{array}$ & $\begin{array}{l}\text { Deciding which } \\
\text { herbal remedy to } \\
\text { use to control } \\
\text { pregnancy-related } \\
\text { symptoms. }\end{array}$ \\
\hline $\begin{array}{l}\text { Descriptions of } \\
\text { Risks and Benefits } \\
\text { Considered }\end{array}$ & $\begin{array}{l}\text { Risks: - Harm to } \\
\text { fetus - Potential } \\
\text { risks of } \\
\text { pharmaceutical } \\
\text { products versus } \\
\text { cannabis - } \\
\text { Involvement with } \\
\text { criminal justice or } \\
\text { child welfare } \\
\text { services Benefits: - } \\
\text { Management of } \\
\text { pre-existing } \\
\text { conditions and } \\
\text { improving general } \\
\text { overall health - } \\
\text { Management of } \\
\text { pregnancy related } \\
\text { symptoms and } \\
\text { conditions }\end{array}$ & $\begin{array}{l}\text { Risks: - Harm to } \\
\text { fetus - Maternal } \\
\text { health, addiction, } \\
\text { stress \& withdrawal } \\
\text { Benefits: - Minor } \\
\text { mentions of benefits } \\
\text { for depression and } \\
\text { other medical } \\
\text { problems }\end{array}$ & $\begin{array}{l}\text { Risks: - Harm to } \\
\text { fetus - Involvement } \\
\text { with criminal } \\
\text { justice or child } \\
\text { welfare services - } \\
\text { Compromised } \\
\text { ability to parent } \\
\text { other children - } \\
\text { Feelings of guilt or } \\
\text { worry - Deteriorated } \\
\text { interaction with } \\
\text { health care } \\
\text { providers } \\
\text { [2]Benefits: - Brief } \\
\text { mentions in quotes } \\
\text { about cost benefits } \\
\text { and stress relief }\end{array}$ & $\begin{array}{l}\text { Risks: -Harm to } \\
\text { fetus Benefit: } \\
\text {-Effective control of } \\
\text { nausea and } \\
\text { vomiting in } \\
\text { pregnancy }\end{array}$ \\
\hline
\end{tabular}




\begin{tabular}{|c|c|c|c|c|}
\hline $\begin{array}{l}\text { How Information } \\
\text { Was Sought and } \\
\text { Used }\end{array}$ & $\begin{array}{l}\text { Sources of } \\
\text { information: - } \\
\text { Healthcare } \\
\text { providers - } \\
\text { Internet - Friends } \\
\text { and Family - } \\
\text { Cannabis retailers } \\
\text { Appraisal of } \\
\text { information: - } \\
\text { Diverse and } \\
\text { conflict- } \\
\text { ing/contradictory } \\
\text { - Lack of clarity } \\
\text { around safety }\end{array}$ & Not mentioned & $\begin{array}{l}\text { Sources of } \\
\text { Information: } \\
\text { related to quitting } \\
\text { substance use and } \\
\text { were acquired } \\
\text { from } \\
\text { substance-abuse } \\
\text { programs }\end{array}$ & $\begin{array}{l}\text { Sources of } \\
\text { Information: - } \\
\text { Prior knowledge - } \\
\text { Trusted sources of } \\
\text { advice (friends, } \\
\text { family, healthcare } \\
\text { providers, } \\
\text { herbalists, the } \\
\text { internet) - } \\
\text { Intuition and } \\
\text { instinct }\end{array}$ \\
\hline
\end{tabular}

Records identified through database

searching

( $n=3569$ )

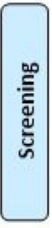

Records after duplicates removed

( $n=3092)$
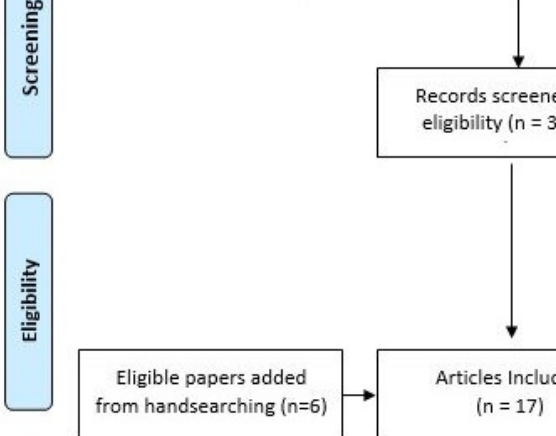

Records screened for

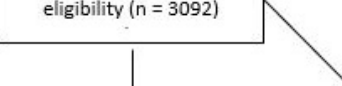

Not empirical $(n=298)$ Not about cannabis ( $n=348$ )

Not about pregnancy or

lactation $(n=320)$

Not available in English ( $n=1)$

Not primary data $(n=560)$

Not published $(n=6)$

Not about attitudes, opinions,

experiences, or beliefs ( $n=1535$ )

Not about pregnant persons and

partners $(n=7)$

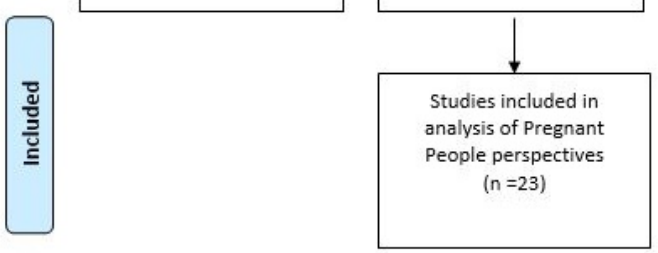

